\title{
Construction of English Park Website
}

\author{
Yan Liu \\ Teaching and Research Institute of Foreign Languages, Bohai University, Jinzhou, 121013, China \\ Liuyan4362@tom.com
}

Keywords: Internet technology; B/S architecture; ASP.NET technology; English park site; functional module

\begin{abstract}
The number of learning English is increasing at an unprecedented speed. The Internet technology with rapid development is applied to learn English, which can help people master the knowledge quickly after leaving the classroom. The system uses B/S architecture, and the structure can greatly reduce the system application' requirements to hardware, while it significantly reduces the difficulty of operating and maintenance of the system, and the workload generated during the upgrade process, which makes the overall cost greatly reduced. And the paper uses ASP.NET technology, its code is easy to write, and it has high reusability and sharing. Finally, the functional modules of English park site were introduced.
\end{abstract}

\section{Introduction}

With the acceleration of globalization, English has become increasingly important, and the future talents can have a foothold that depends on mastering English to some extent [1]. According to the survey, the number of learning English in our country occupies 25 percent of the world. Faced with so much information requirements, traditional English learning characterized by textbooks, classrooms and various courses are not satisfy people's needs. Development and application of the Internet is changing people's work, life, and study and interaction way. Internet technology can be applied to English learning that can improve people's interest, efficiency and initiative of learning. In order to meet the demand for learning English, it is necessary to construct English learning website. In this site, English teachers can easily access the latest materials and a variety of tutorials through Internet, materials should be processed and finished, and then put on those to their English website; students can overcome time and space limitations, using the Internet to obtain information related to the classroom, or they can browse according to their interests. Today, it is particularly important to built and use English website for students to create a positive, active and independent learning environment and atmosphere. The construction of website has great significance in enriching and improving the traditional English teaching and learning, cultivating students' comprehensive ability in English application and English thinking [2].

\section{The Architecture of English Park Site}

The system uses B/S that is browser/server architecture, which is a new MIS system platform mode based on technology. The server in traditional model can be decomposed into a data server and one or more application servers, and a client-server system with three-layered structure can be constituted [3], it is shown in Fig. 1. In this structure, the UI for front-end users mainly is achieved by a browser (such as IE, Firefox, etc.) and the corresponding WEB pages, the front-end (browser) also handles business logic, but only a very small section, and a large number of major business logic is carried on the server-side (server).

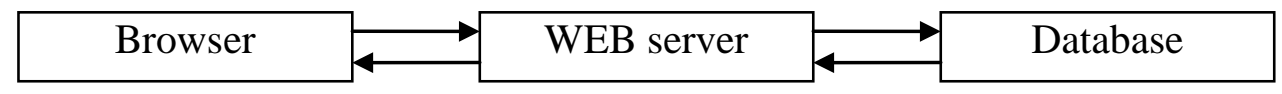

Fig. 1. The architecture of English park site

As shown in Fig. 1, in B/S structure, users run the browser software on the client, and issue a request to $\mathrm{B} / \mathrm{S}$ server by the browser, $\mathrm{B} / \mathrm{S}$ server receives the request and process the request, the 
request should be converted to SQL statement firstly, and giving SQL statement to the database server to verify its validity and processing data, and then processed results should be returned back to the $\mathrm{B} / \mathrm{S}$ server, finally, the result is returned to the browser by B/S server, the browser displays the result at the form of Web page [4].

$\mathrm{B} / \mathrm{S}$ architecture is generally divided into three levels: the first layer is the client browser, which is the interface between the students and the whole system; the second layer is the web server, it is the client's background; the third layer is the database server, its mission is to manage the database.

B/S structure has two main advantages [5]:

(1) Simple to maintain and upgrade. Currently, the improvement and upgrading of software systems become more frequent, the products of $\mathrm{B} / \mathrm{S}$ architecture embody more convenient features. The software of B/S architecture only needs to manage the server, and all clients only are browsers, so there is no need for any maintenance. No matter how many users and branches, those will not increase the workload of maintenance and upgrading, all operations only counter servers; if it is remote, server only needs to connect with a private network to realize remote maintenance, upgrading and sharing.

(2) Lower costs and more options. Everyone knows that windows almost rules all the land in the desktop computers, the browser has become a standard configuration, but on server operating system, windows is not in the absolute dominance. The current trend is that application management software with B/S structure just needs to be installed on a Linux server, and it has high safety. Therefore, the choice of server operating system is a lot, but regardless of the choice, most people use windows as a desktop operating system is not affected.

However, B/S structure also has a disadvantage:

(3) The load of data run on the application server is heavy. Because management software of B/S architecture is only installed on the server, transaction logic of the user interface completely is realized through a browser on the server, very small part of the transaction logic is implemented in browser, all clients only have browser, so network managers need to do hardware maintenance. However, the load of data run on the application server is heavy, the consequences could be disastrous once a server "crashes" and other issues are occurred. Therefore, many units are equipped with database storage server just in case.

\section{The Key Technology of English Park Site}

The site uses ASP.NET technology to design web. ASP.NET is an application framework based on universal language. A compiled and .NET-based environment, the universal language-based program runs on the server. It is part of the .NET FrameWork and a technology belonged to Microsoft, and it also is a server-side script technology that makes script embed Web page be executed on Internet server, which can be dynamically created on the Web server when HTTP request document [6].

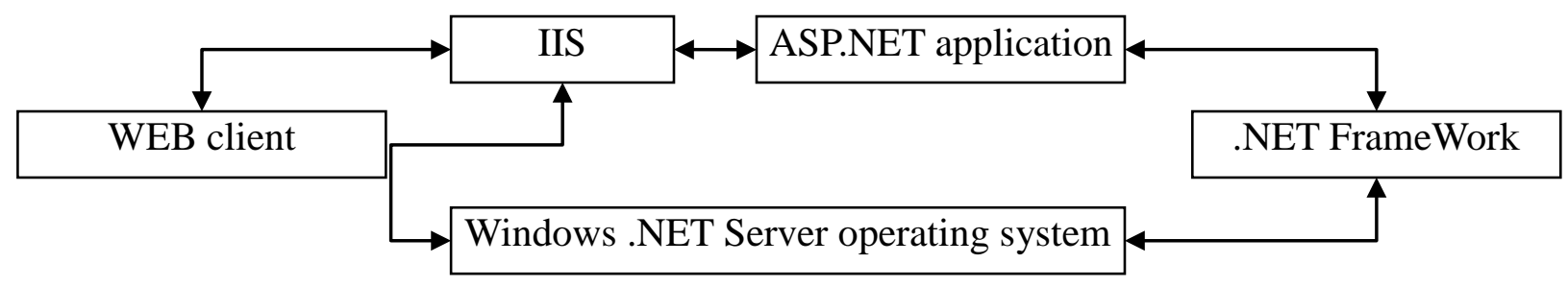

Fig. 2. The diagram ASP.NET

As shown in Fig. 2, all clients use IIS to communicate with ASP.NET applications. IIS interprets the requests and authenticates requests selectively. If the "allow anonymousness" is set to true, it will not be authenticated. IIS will also find requested resources (such as ASP.NET applications), if the client has been authorized, it will return the appropriate resources. In addition to the built-in features of ASP.NET, ASP.NET applications can also use the low-level security features of .NET Framework.

ASP.NET has a few features: 
(1) Cross-platform. Because ASP .NET is a program based on the universal language, its realization is fully dependent on the virtual machine, it has characteristic of cross-platform, and applications used ASP .NET can run on almost all platforms.

(2) Easy to learn. ASP.NET makes some common tasks very simple, such as submission of forms, authentication for client, distribution of system and configuration of site. For example, framework of ASP.NET page allows you to build your own user interface, which makes it different from the common VB-Like op.

(3) Manageability. ASP.NET uses a character-based and hierarchical configuration system, so setting up virtual server environments and applications is easier. Because the configuration information is stored in simple text, the new setting may not need to start a local administrator tool to achieve. This concept allows the application-based development of ASP.NET more specific and faster. An ASP.NET application only need to copy some required files when installs on a server system without restarting the system, everything is so simple.

\section{Function Design of English Park Site}

The contents of this site main include six modules: they are management module, resource module, learning module, test module and discussion module. And Function structure diagram is shown in Fig. 3.

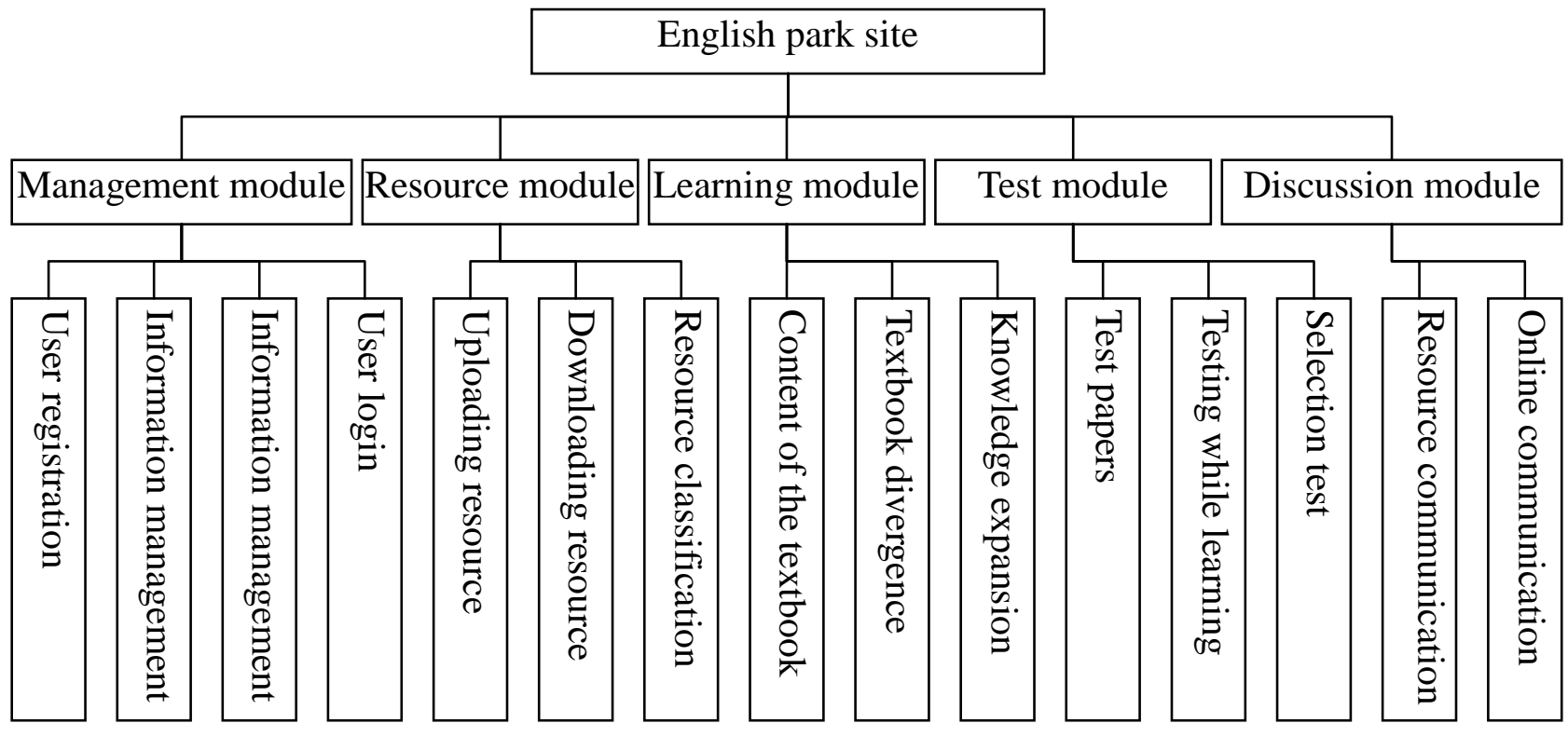

Fig. 3. Function structure diagram of English park site

1. Management module. Our designed management module of website should contain two parts: one is for the users, and the other is for the backstage managers. Management module for the users includes the user's login, registration, and personal information and so on; management module for the backstage managers includes system maintenance, upgrade, and routine maintenance of database and optimization of site.

2. Resource module. Site provides a number of systemic learning resources to provide the latest learning resources for teachers and students, which can help students to learn effectively and successfully pass the exam. Pictures, texts, videos, games and other material involved in Website, are downloaded after authorization.

3. Learning module. Website managers enter their own management pages, they can directly manage categories, add articles, upload learning resources and others with their own permission. The system is fast and easy to manage, website managers can save a lot of time, so they can concentrate on seeking, collecting and organizing information in order to better perfect and enrich the site contents. 
4. Test module. When learners want to test their knowledge on the site, they can issue a request for the exam on the site, the user can choose the direction of the examination according to their own knowledge, when they finished, the system will choose a set of questions for learners based on the learner's request. After the test, the system will mark and then give scores for the submitted paper. Learners can timely study knowledge not mastered according to the exam situation [7].

5. Discussion module. This module provides a free exchange and cooperation platform for English learners. Learners can communicate with each other or discussion their own problems, ideas with other learners and teachers, and they also can post open questions on platform to share with others.

\section{Conclusion}

Self-learning network platform as the product of reform and informatization can achieve a great help for students' learning. In this site, using B/S architecture and ASP.NET technology to design English park website. Firstly, B/S architecture and ASP.NET technology was introduced briefly, as well as their features and workflows. Finally, each module of the site was described in detail. As an auxiliary and an extension of traditional classroom, English learning website broke the simple studying model of demonstration [8]. The website uses entertaining way to provide a new learning way for learners, so that learners have a strong interest in learning to lay a solid foundation for later learning. The site effectively promotes learners to study English, learners can communicate with others and share resources in the platform, while taking into account the entertainment and learning, so the learning efficiency can be improved effectively [9]. English learning website can update and improve constantly to better play its role in developing learners' language ability. This computer-assisted English learning is worth further exploring in order to better service for English studying. The designed site is more convenient and efficient to manage the music [10].

\section{References}

[1] Z. Z. Shi, "Study of Information Architecture of English Learning Resources Web Sites," Master's degree of Tianjin Foreign Studies University, 2008.

[2] P. Wang, "Junior High School English Subject Situational Website Designing Research," Master's degree of Northeast Normal University, 2013.

[3] G. M. Wang, "Design and Implementation of Undergraduate Thesis Selection System in Higher Education Institutions," Master's degree of Amoy University, 2013.

[4] J. K. Huang, "Design and Implementation of the Hotel Management System Based on B/S," Master's degree of University of Electronic Science and Technology of China, 2013.

[5] Baidu Encyclopedia, "B/S," http://baike.baidu.com/link?url=rf_I0sReOnQ1XcHmggB-FB58x, 2015-1-6.

[6] Baidu Encyclopedia, "ASP.NET," http://baike.baidu.com/link?url=9zQVTyjDE9ZZfZoyUy_I, 2015-1-6.

[7] Y. H. Yang, "Design and Development of Mobile Learning Website for English Learning Serving the Foreign-related Catering," Master's degree of Hebei University, 2014.

[8] Q. Wang, Y. M. Zhang, X. C. Chen, "The construction of English learning website and the influence for training learners' ability," vol. 30, no. 5, pp. 129-130, 2010.

[9] X. X. Li, "Design and development of language website of foreign literature in the sixth grade," Primary and Middle School Educational Technology, vol. 34, no. 9, pp. 63-66, 2011.

[10] H. M. Yuan, X. F. Ding, "Design on the music website based on ASP technology," Science \& Technology Information, vol. 28, no. 8, pp. 628, 2011. 